\title{
Crisis y desarrollo geográfico desigual en la Unión Europea $(2009-2015)^{1}$
}

\author{
María Antonia Martínez Caldentey² e Ivan Murray³:
}

\begin{abstract}
RESUMEN
El objetivo central del artículo consiste en indagar el impacto de la crisis financiera de 2008 en las diferentes regiones de la Unión Europea (UE) y reflexionar sobre el propio proceso de construcción de una UE a múltiples velocidades. Para ello se parte del marco teórico de la geografía económica crítica y en concreto la teoría del Desarrollo Geográfico Desigual (DGD). Metodológicamente se han aplicado técnicas de análisis espacial, combinando análisis factorial y clúster a nivel regional (NUTS-2) que luego son plasmados cartográficamente. Este análisis se aplica en dos momentos: el primero coincide con la mayor caída del PIB de la UE (2009); y el segundo corresponde con la situación posterior a la aplicación a las políticas de ajuste y austeridad (2015). Los resultados del estudio indican que con la crisis se ha acentuado el desarrollo geográfico desigual en el seno de la UE.
\end{abstract}

Palabras clave: Crisis Financiera, Geografía Económica Crítica, Desarrollo Geográfico Desigual, Unión Europea, NUTS-2.

\begin{abstract}
The main purpose of this paper is to analyse the impact of the 2008 financial crisis in the different regions of the European Union (EU) and think over the construction of the European project at multiple speeds. Theoretically the research is grounded on critical economic geography, and particularly on the theory of Uneven Geographical Development. Methodologically, we have applied spatial analysis techniques, combining factor and cluster analysis at regional level (NUTS-2). And those results are mapped. The analysis is applied in two moments: the first one coincides with the highest decline in the EU's GDP (2009); and the second corresponds to the situation after the implementation of the adjustment and austerity policies (2015). The results of the study indicate that the crisis has accentuated the uneven geographical development within the EU.
\end{abstract}

Key words: Financial Crisis, Critical Economic Geography, Uneven Geographical Development, European Union, NUTS-2.

La investigación que da lugar a este artículo se inscribe en el proyecto titulado "Crisis y reestructuración de los espacios turísticos del litoral español" (CSO2015-64468-P) del Ministerio de Economía y Competitividad (MINECO) y del Fondo Europeo de Desarrollo Regional (FEDER). Artículo recibido el 6 de enero de 2018, aceptado el 4 de septiembre de 2018 y corregido el 8 de septiembre de 2018. 
El sistema-mundo capitalista, cada vez más globalizado e interdependiente, se caracteriza por la creciente aceleración de los procesos socio-espaciales. Desde los inicios del neoliberalismo, las crisis se han multiplicado y sus efectos se han hecho cada vez más intensos y extensos. Independientemente de dónde se ubiquen las causas de una determinada perturbación o crisis, sus impactos se propagan inmediatamente espacio-temporalmente. No obstante, no todos los espacios ni grupos sociales están sujetos a los impactos de las crisis de la misma manera, sino que se manifiestan de manera diferenciada. En este sentido, las crisis pueden profundizar las dinámicas de diferenciación socio-espacial. De este modo, nos podemos encontrar grupos sociales y espacios que salen reforzados gracias a las crisis, mientras que otros asumen los costes sociales (Harvey, 2014).

En este contexto, la construcción de la UE se puede comprender como un proyecto de los centros de poder para actuar colectivamente por encima de las fronteras estatales y convertirse en un actor central del capitalismo global, una especie de macroestado (Fernández-Durán, 2005). Sin embargo, más allá de su papel como actor global, el territorio de la UE se caracteriza por su enorme complejidad y diversidad, organizándose en torno a los grandes espacios urbano-industriales, que a su vez forman ejes de carácter transfronterizo, tejidos por densas redes de comunicación. Por otro lado, aquellas regiones que no se ubican en las coordenadas de esos centros del capital, han ido quedando progresivamente desplazadas del proyecto europeo. Y, para ello se ha dispuesto toda una serie de paquetes de medidas dirigidas a fomentar una teórica cohesión europea, pero que tal como sostienen Hadjimichalis \& Hudson (2014) dichos planteamientos de cohesión parten de una concepción ageográfica que se asienta en una pobre noción de las diferentes condiciones geohistóricas del conjunto de regiones de la UE. Además, tal como ha señalado Brenner (1999: 447) la UE condensa las tensiones de la redefinición escalar del capital caracterizadas por el "carácter multi-estratificado, densamente entretejido y altamente contradictorio de las prácticas espaciales contemporáneas".

La génesis de la UE tiene sus inicios al finalizar la Segunda Guerra Mundial, cuando el proyecto europeo se postuló como el arreglo espacial a esa gran crisis. El motor de la construcción europea fue tanto geoeconómico, mediante la constitución de un Mercado Único (Varoufakis, 2012), como geopolítico, entendido como un muro de contención ante el avance del socialismo real (Garcés, 2008). Con la firma del Tratado de Roma (1957) se creó la Comunidad Económica Europea (CEE) que consistía en una gran área de libre comercio y circulación de capitales que se articulaba en torno a Alemania occidental, protegida por los EE. UU. y financiada con el Plan Marshall (Fernández-Durán, 2005; Varoufakis, 2012). Durante los "Treinta Gloriosos", con el auge de las políticas keynesianas, la economía europea experimentó una fuerte expansión que tenía como ejes centrales una intensa urbanización e industrialización. Ya en plena crisis del capitalismo regulado, en los setenta, se incorporaron a la CEE el Reino Unido, Irlanda y Dinamarca, iniciándose un proceso de redefinición territorial del proyecto europeo, que sería cada vez más complejo y contradictorio (Fernández-Durán, 2005). Asimismo, la crisis de los setenta significó el agotamiento del régimen fordista y el inicio de la reestructuración neoliberal europea. La implantación de las lógicas espaciales del capital, cada vez más financiarizadas, encontraron su acomodo institucional en la creación del Mercado Único y la implantación del euro (Fernández-Durán, 2005; Streeck, 2017).

A partir de la firma del Acta Única (1985) se llevó a cabo la supresión de controles fronterizos entre los Estados miembros, dando lugar al llamado espacio Schengen. Ello permitía la configuración de un circuito espacial de mercancías, capitales, servicios y personas sin apenas fricción. 
En los ochenta, en plena construcción de la Europa neoliberal, se adhirieron al proyecto europeo los Estados meridionales -Grecia, España y Portugal-, inaugurando el inicio de la Europa a distintas velocidades que se ampliaría posteriormente hacia el este. La doctrina neoliberal se asentó con el Tratado de Maastricht (1991), con el que se aprobó la creación de la Unión Económica y Monetaria (UEM), y el Tratado de Lisboa (2007) que consolidaba una política europea monetarista y con elevados déficits democráticos. De hecho, dicho tratado sustituyó lo que debía ser el Tratado de la Constitución Europea debido a las fuertes resistencias sociales que suscitó (Fernández-Durán, 2005; Streeck, 2017).

La política europea, articulada en torno al euro, se sostenía sobre estructuras económicas dispares: por un lado, Estados con superávits comercial y/o financiero, que exportaban capitales y mercancías a los Estados periféricos; y, por otro, esos otros Estados deficitarios que resultaban clave para el sostenimiento de las potencias regionales. La especialización productiva de las regiones en la división internacional del trabajo a escala UE fue produciendo unas dinámicas paralelas de desindustrialización (centro y semi-periferia), centralización de dirección y mando del capital (centro), reindustrialización periférica, especialización rentista turístico-inmobiliaria en los Estados mediterráneos (semi-periferia). La falta de políticas de compensación geoeconómica, como un sistema impositivo común, suponía un elevado riesgo para la estabilidad de la propia UE (Varoufakis, 2012; Lehndorff, 2015; Hadjimichalis, 2018).

El estallido de la crisis financiera en los EE. UU. del 2008 se propagó rápidamente por el sistema mundo-capitalista, desplazándose desde la economía financiera a la real. En un inicio, más que una crisis global se trató de una crisis de los espacios centrales del capitalismo avanzado, azotando intensamente la UE (Lapavitsas, 2012; Lehndorff, 2015; Subasat, 2016). A diferencia de los EE. UU. donde se llevaron a cabo políticas de rescate financiero y estímulo de la economía, la UE combinó políticas de rescate financiero, ajuste y austeridad (Schäfer y Streeck, 2013; Lehndorff, 2015). La deuda privada se convirtió progresivamente en deuda pública y los Estados del sur, los llamados despectivamente PIGS, fueron sometidos a la férrea disciplina de las políticas austericidas dictadas por la Troika (BCE, CE, FMI) (Lapavitsas y Flassbeck, 2015). Sin embargo, las políticas anticrisis no han hecho más que ampliar y reforzar la diferenciación socioespacial, destacando por un lado la hegemonía alemana, y por otro los procesos de desintegración y desafección respecto del proyecto europeo (Streeck, 2017).

Después de esta breve introducción a la construcción de la UE vamos a proceder con el análisis del desarrollo geográfico desigual en la UE. A pesar de haber numerosas aportaciones sobre las contradicciones del proyecto europeo y las desigualdades territoriales, la mayor parte de éstas se centran en una comparación entre los Estados miembros y al analizarse las regiones no suele abordarse el conjunto del espacio UE, sino que se suelen concentrar en las diferentes dinámicas regionales dentro de un determinado Estado-miembro. Así, de acuerdo con Hadjimichalis \& Hudson (2014) podemos decir que el análisis regional incluso se llega a realizar de manera aislada o descontextualizada, enfatizando en muchas ocasiones aquellos elementos de éxito económico derivados de la adhesión al proyecto europeo, mientras que se soslayan las tensiones y conflictos socioespaciales. A partir de la revisión bibliográfica se ha detectado un cierto vacío a la hora de analizar las tensiones socioespaciales del conjunto de la UE a escala regional, que será precisamente nuestro objeto de estudio. Ello implica un análisis transescalar entendiendo la UE como una entidad geopolítica, formada por sus Estados miembros, los cuales conforman unas geografías regionales desiguales. Por otra parte, el artículo trata la incidencia de la crisis a nivel regional 
en el contexto de la UE, con el objetivo de evaluar qué papel ha jugado la crisis en las desigualdades regionales. Para ello, en primer lugar, se introduce el marco teórico del desarrollo geográfico desigual y algunas de las principales aportaciones. En segundo lugar, se presenta la metodología utilizada para el análisis empírico a partir de técnicas multivariantes. En tercer lugar, se procede a presentar y analizar los resultados obtenidos. Finalmente, el artículo se cierra con unas conclusiones que pretenden abordar diferentes cuestiones surgidas a raíz de esta investigación.

\section{La Teoría del Desarrollo Geográfico Desigual (DGD)}

El concepto formulado por Trotsky del Desarrollo Desigual y Combinado (DDC) ha tenido una influencia fundamental en la economía política marxista. Particularmente en la década de los setenta la teoría DDC incidió en autores como Samir Amin (1974), en el marco de las teorías de la dependencia, o Immanuel Wallerstein (1979) con su formulación de la teoría sistema-mundo. Con el giro intelectual de David Harvey y la irrupción de la geografía crítica en esos años, el concepto del Desarrollo Geográfico Desigual (DGD) sería clave para explicar los profundos cambios del capitalismo global y sus lógicas espaciales. En este sentido, en los ochenta aparecen las profundas reflexiones teóricas de Harvey (2006 [1982]), Smith (2010 [1984]) o Massey (1995 [1984]) sobre las geografías del capital, que sientan las bases de la teoría del DGD. En el ámbito europeo cabe destacar el trabajo de Hadjimichalis (1987) sobre la Europa meridional a partir de la teoría del DGD.

La teoría del DGD, entendida como un marco teórico dinámico y abierto, ha sido una de las principales vías de investigación de la geografía económica, según la cual la desigualdad socio-espacial es intrínseca a la geografía capitalista y fundamental para la reproducción ampliada del capital. En las dinámicas espaciales del capital se detectan dos tendencias paralelas y contradictorias: por un lado, la ecualización u homogeneización geográfica, lo que conduce a una caída de la tasa de beneficio como resultado de la lucha competitiva inter-territorial; $y$, por otro, la diferenciación geográfica, como estrategia para relanzar la tasa de beneficio y alcanzar una posición de dominio, en la captura de las rentas monopolísticas, respecto al resto de territorios. Así pues, el DGD no es estático, sino que se establece sobre un conjunto de disparidades dinámicas entre las distintas escalas geográficas, que se van articulando a lo largo de los cambios del capitalismo histórico con las diferentes reformulaciones del régimen de acumulación capitalista. Es lo que Neil Smith define como el movimiento en "balancín" del capital (sea-saw). Las crisis son, bajo este prisma, momentos en los que emergen las contradicciones del capital y en los que se producen procesos de devaluación y destrucción, por un lado; mientras que por otro se articulan nuevos arreglos espaciotemporales a través de los cuales canalizar los excedentes del capital, todo ello reproduciendo las lógicas del DGD (Harvey 2006 [1982]; Harvey, 2014; Smith, 2010 [1984]).

El triunfo del neoliberalismo fue acompañado en el ámbito académico del arrinconamiento de los enfoques críticos y la aparición de nuevas aportaciones tributarias de la teoría neoclásica, como la Nueva Geografía económica o la nueva teoría del desarrollo regional (Hadjimichalis y Hudson, 2014). El estallido de la crisis de 2008 ha puesto en evidencia las insuficiencias de la teoría neoclásica ${ }^{4}$ al mismo tiempo que se ha producido un auge de la teoría DGD. Tal como señalan

El predominio de la economía neoclásica en el mundo académico y en los principales centros del poder mundial ha sido señalado por diversos autores como un elemento clave a la hora de explicar el estallido de la crisis, así como el aumento de las desigualdades sociales y con- 
Hadjimichalis y Hudson (2014: 214-215): "la crisis de las teorías dominantes del desarrollo regional indica claramente que es el momento para un cambio de paradigma". Según esos autores, este giro debería combinar la economía política, las lecciones de los movimientos sociales emancipatorios, así como algunos elementos de las nuevas teorías del desarrollo regional.

Además, la crisis ha hecho que la cuestión de la desigualdad haya vuelto a ocupar un lugar central en el debate social (Wlikinson \& Pickett, 2010; Piketty, 2014), contribuyendo a la revitalización de las teorías críticas y la reflexión sobre la cuestión de la desigualdad desde múltiples enfoques y disciplinas. Es pues en dicha revitalización del debate sobre la desigualdad, que la teoría del DDC y del DGD han cobrado un nuevo vigor (Hadjimichalis \& Hudson, 2014; Dunford y Liu, 2017). De esta manera, una de las elaboraciones teóricas más destacadas es la llevada a cabo por Desai (2016) bajo el término de economía geopolítica. Mientras que, en el ámbito europeo, Costis Hadjimichalis es quien ha realizado las aportaciones más destacadas a partir de la teoría del DGD en el contexto de la crisis (Hadjimichalis, 2018). Así mismo, en el ámbito español, desde la geografía humana también se han abordado las geografías de la crisis, haciendo especial hincapié en la transescalaridad del capital y las desiguales materializaciones socioespaciales de la crisis (Albertos y Sánchez, 2014; Méndez et al., 2015).

\section{Metodología}

Un aspecto que ya se ha avanzado es el hecho que una gran parte de los trabajos que se han realizado en el marco de la teoría del DGD se han centrado fundamentalmente en técnicas cualitativas y, en todo caso, se han utilizado herramientas cuantitativas a nivel estatal (González, 2011; Hadjimichalis, 2011). Ello se debe fundamentalmente a dos motivos: en primer lugar, el abandono de las herramientas cuantitativas por parte de la geografía crítica; y, en segundo lugar, la escasez de datos robustos a nivel infraestatal para el conjunto de los Estados miembros de la UE. No obstante, podemos sostener, siguiendo a Wyly (2011), que las técnicas cuantitativas no deben ser abandonadas al uso exclusivo de los enfoques conservadores, sino que éstas pueden ser extraordinariamente útiles para la construcción de las narrativas contra-hegemónicas, y por ello pueden jugar un papel clave en el vigor de una geografía radical y socialmente comprometida.

Este análisis, por tanto, pretende abordar el DGD entre las diferentes regiones de la UE mediante la hibridación de técnicas cuantitativas y cartográficas con el análisis crítico. La unidad espacial analizada son las NUTS-2 (Nomenclatura de las Unidades Territoriales Estadísticas) -población entre 3.000 .000 y 800.000 habitantes-, que en el Estado español corresponden a las comunidades autónomas. Así, el conjunto de la UE-28 se divide en 279 NUTS-2, entendidas como un marco territorial óptimo para la realización de estudios de carácter estadístico a nivel regional (Kotzeva, 2016). La parte principal de la investigación se ha centrado en la aplicación de la estadís-

flictos ecológicos. Dichos autores entienden que la economía neoclásica es uno de los aparatos centrales del poder. El paradigma neoclásico se caracteriza por una noción reduccionista del sistema económico que lo desvincula de su contexto geohistórico. Así, de acuerdo con los parámetros de la teoría neoclásica, los sistemas económicos deben tender a situaciones de equilibrio, entendiendo las crisis como algo ajeno al propio sistema económico. Las causas de las crisis de acuerdo con este paradigma se buscan en las limitaciones y presiones que dicen se ejercen sobre el "libre" funcionamiento del mercado, lo cual acabaría distorsionándolo y derivando en situaciones de crisis y recesión. Para una lectura completa y crítica sobre las insuficiencias de la teoría neoclásica se recomienda consultar las obras de David Harvey (2006 [1982], 2010); Steve Keen (2011); José Manuel Naredo (2015 [1987]) o Anwar Shaikh (2016). 
tica multivariante a los ámbitos de estudio, siendo una técnica bastante usada en la investigación geográfica (Bosque y Moreno, 1994; Rogerson, 2014). Se puede señalar que el uso de dicha técnica ha ganado peso en los últimos tiempos para el análisis de la desigualdad y vulnerabilidad espacial, tanto a escala urbana (Alguacil et al., 2014), como regional (Méndez et al., 2015). Ello se debe, por un lado, al aumento del volumen de información disponible para esas escalas geográficas; y, por otro, por la capacidad explicativa que ofrece el análisis multivariante, gracias a la síntesis factorial de múltiple y compleja información. Las aportaciones citadas anteriormente ofrecen una lectura crítica de los procesos urbanos y regionales a partir de un análisis estadístico sólido en el contexto de la crisis en España.

Para la clasificación de las diferentes regiones se han aplicado dos tipos de operaciones dentro del análisis multivariante, utilizando el programa estadístico IBM-SPSS: el análisis factorial y el análisis clúster. El análisis factorial es una técnica estadística que se utiliza para la reducción de datos, mediante la cual se obtienen grupos homogéneos de variables altamente correlacionadas entre sí, los factores. En último lugar, una vez se han obtenido las puntuaciones factoriales correspondientes a cada unidad espacial y de cada factor, éstas se representan cartográficamente mediante un Sistema de Información Geográfica (programa ArcGIS), lo que aumenta la capacidad de análisis de los diferentes patrones regionales de cada factor (Bosque y Moreno, 1994; Santos y García, 2008; Rogerson, 2014). La última etapa del análisis estadístico-cartográfico, corresponde al análisis clúster mediante el método jerárquico aglomerativo Ward, con la intención de intentar discernir agrupaciones espaciales de NUTS-2 similares entre sí a partir de los factores obtenidos en la fase anterior (Bosque \& Moreno, 1994; Vilà et al., 2014).

Finalmente, debemos hacer un breve comentario sobre los años seleccionados y los datos analizados para esta investigación. En primer lugar, si atendemos a la evolución del PIB en el conjunto de la UE28 se detecta como en el 2009 se registró el mayor descenso y posteriormente el agregado de renta se iría recuperando (Figura $\mathrm{N}^{\circ} 1$ ). De todos modos, tal como puede apreciarse en la figura 1, el valor del PIB de la UE28 se ve arrastrado fundamentalmente por el peso de las economías más potentes que, de hecho, retomaron la senda expansiva después de los rescates bancarios; mientras que en las regiones del Sur de Europa la economía siguió deprimiéndose, dando pie a las políticas de choque -austeridad y ajuste- cuando la crisis financiera mutó en crisis de la deuda soberana en Grecia hacia finales de 2009. Así, no es casual que la recuperación de las economías centrales coincida con la profundización de la crisis en las periféricas (Schäfer y Streeck, 2013; Hadjimichalis 2018). De esta manera, los años seleccionados han sido el 2009 por lo comentado anteriormente, y el 2015 que corresponde con el momento de recuperación económica dentro del marco de las políticas de austeridad, así como del que se disponen con datos más actualizados.

En segundo lugar, la selección de los datos ha sido una de las tareas más laboriosas de la investigación, ya que debíamos contar con información de calidad para cada una de las NUTS-2 analizadas en los años seleccionados. Para ello se ha contado con la base de datos regional de EUROSTAT ${ }^{5}$. Por un lado, la información seleccionada ha sido la más completa al nivel de desagregación requerido, pero seguramente el estudio hubiera sido más sólido con un mayor abanico de variables relacionadas con el objeto de estudio. Por otro lado, el interés por el comportamiento 
de las regiones españolas y por el hecho que la intensificación turística haya sido una de las estrategias de salida de la crisis (Murray, 2015), nos ha llevado a contemplar variables turísticas. Finalmente, se han seleccionado para los años 2009 y 2015 las siguientes diez variables: (1) salario medio; (2) PIB/cápita; (3) deuda pública expresada en porcentaje de PIB; (4) proporción de población mayor de 25 años con educación universitaria; (5) gasto en I+D per cápita; (6) proporción de personas entre 18 y 24 años que ni trabajan ni estudian; (7) desempleo (tasa de paro); (8) intensidad de empleo por hogar (proporción de personas que viven en hogares con intensidad muy baja respecto la población total); (9) riesgo de pobreza y exclusión social (proporción de personas con ingresos por debajo del umbral de riesgo de pobreza); (10) porcentaje de trabajadores del sector turístico respecto al empleo total; (11) pernoctaciones turísticas por habitante.

Figura $N^{\circ} 1$

Evolución del PIB (Euros constantes 2010) en la UE-28, 2007-2016 (PIB 2007 = 100)

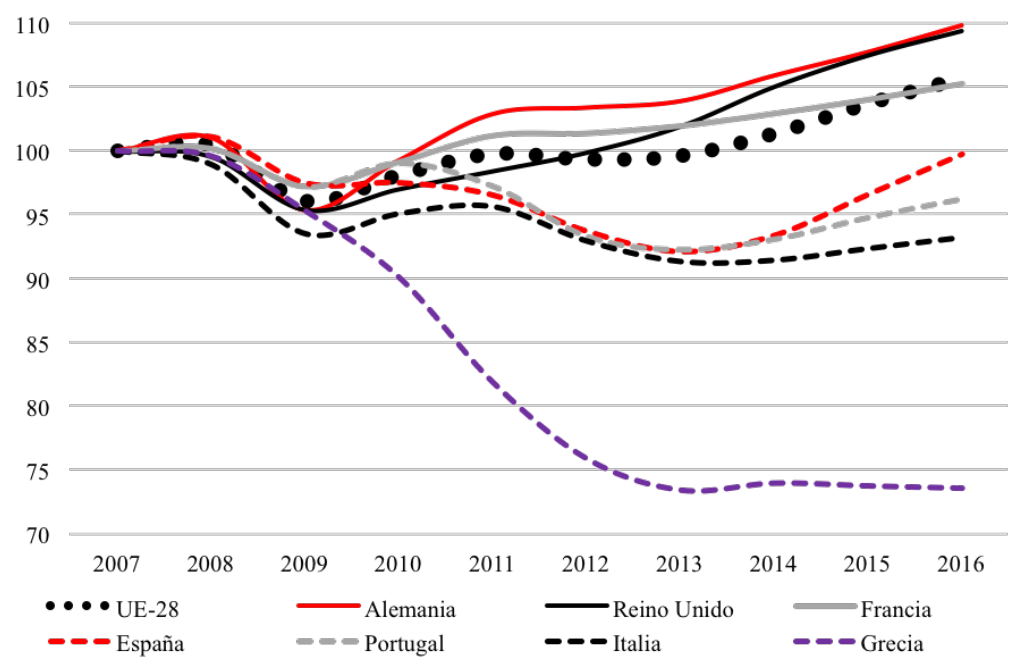

Fuente: Elaboración propia a partir de EUROSTAT.

\section{EI DGD en las regiones de la UE28. Del estallido de la crisis (2009) a la austeridad (2015)}

A partir del análisis de componentes principales se han obtenido tres factores en el año 2009 y para el 2015. En el año 2009, se obtienen tres factores que explican el 68,58\% de la varianza total acumulada de la matriz factorial rotada. El primer componente representa el $30,07 \%$ de la varianza y correspondería al nivel socioeconómico y cualificación profesional, ya que las variables predictoras son el salario medio, el PIB per cápita, el gasto en I+D y la proporción de la población con educación superior. El segundo componente explica el 20,91\% de la varianza y lo definimos como el factor de precariedad laboral y vulnerabilidad social, ya que presenta unos valores de saturación elevados en las variables de jóvenes que no estudian ni trabajan, desempleo, riesgo de pobreza y hogares con poco trabajo. En cierta manera, este segundo componente se podría interpretar como el reverso del primer factor. El tercer componente, con un $17,60 \%$ de la varianza total, corresponde a la intensidad turística, al estar representado por las variables densidad de pernoctaciones turísticas y empleo turístico (Cuadro $N^{\circ} 1$ ). 


\section{Cuadro $\mathrm{N}^{\circ} 1$}

Matriz de componentes rotada, 2009

\begin{tabular}{|l|r|r|r|}
\hline \multirow{2}{*}{ Variables } & \multicolumn{3}{|c|}{ Componente } \\
\cline { 2 - 4 } & \multicolumn{1}{|c|}{1} & \multicolumn{1}{|c|}{3} \\
\hline (1) Salario medio & 0,932 & & \\
\hline (2) PIB/cápita & 0,886 & $-0,247$ & 0,215 \\
\hline (5) I+D & 0,811 & $-0,209$ & \\
\hline (4) Educación Superior & 0,740 & & $-0,223$ \\
\hline (6) Jóvenes sin trabajo/sin estudios & $-0,277$ & 0,840 & \\
\hline (7) Desempleo & & 0,774 & \\
\hline (9) Riesgo de pobreza & $-0,433$ & 0,662 & \\
\hline (8) Hogares con poco trabajo & 0,401 & 0,603 & \\
\hline (10) Empleo turístico & & 0,208 & 0,831 \\
\hline (11) Pernoctaciones turísticas & & & 0,821 \\
\hline (3) Deuda Pública & & & 0,600 \\
\hline
\end{tabular}

Fuente: elaboración propia a partir de EUROSTAT.

Para el año 2015, se han extraído los mismos tres factores que explican el 74,89\% de la varianza de la matriz rotada, diferenciándose del 2009 en que los componentes primero y segundo explican prácticamente la misma varianza. Es decir, el factor socioeconómico y el de la precariedad social se han aproximado, siendo un claro síntoma de los efectos de la crisis. El primer componente corresponde al factor socioeconómico y cualificación, representando el 30,05\% de la varianza, y contiene las variables salario medio, PIB per cápita, gasto en I+D y población con estudios superiores. El segundo factor, con las variables hogares con poco trabajo, desempleo, riesgo de pobreza y jóvenes que no estudian ni trabajan, recoge el $28,59 \%$ de la varianza y lo definimos como el factor de precariedad laboral y vulnerabilidad social. Finalmente, el tercer componente, con el $16,25 \%$ de la varianza, corresponde a la intensidad turística, representado por las variables pernoctaciones turísticas y empleo turístico.

\section{Cuadro $\mathrm{N}^{\circ} 2$}

Matriz de componentes rotada, 2015

\begin{tabular}{|l|r|r|r|}
\hline \multirow{2}{*}{ Variables } & \multicolumn{3}{|c|}{ Componente } \\
\cline { 2 - 4 } & \multicolumn{1}{|c|}{1} & \multicolumn{1}{|c|}{2} & 3 \\
\hline (1) Salario medio & 0,933 & & \\
\hline (2) PIB/cápita & 0,922 & & \\
\hline (5) I+D & 0,794 & & \\
\hline (4) Educación Superior & 0,770 & & \\
\hline (4) Hogares con poco trabajo & & 0,844 & \\
\hline
\end{tabular}


Continuación Cuadro $N^{\circ} 2$

\begin{tabular}{|l|r|r|r|}
\hline \multirow{2}{*}{ Variables } & \multicolumn{3}{|c|}{ Componente } \\
\cline { 2 - 4 } & \multicolumn{1}{|c|}{1} & \multicolumn{1}{|c|}{3} \\
\hline (7) Desempleo & $-0,207$ & 0,810 & \\
\hline (9) Riesgo de pobreza & $-0,350$ & 0,794 & \\
\hline (6) Jóvenes sin trabajo/sin estudios & $-0,416$ & 0,766 & \\
\hline (3) Deuda Pública & & 0,592 & 0,466 \\
\hline (11) Pernoctaciones turísticas & & & 0,919 \\
\hline (10) Empleo turístico & & 0,374 & 0,807 \\
\hline
\end{tabular}

Fuente: elaboración propia a partir de EUROSTAT.

A continuación, se han cartografiado a modo de resultados los factores para ambos años, de forma que se puedan observar las distintas dinámicas territoriales que se producen en la UE, así como la evolución que han experimentado las distintas regiones analizadas durante la crisis. Los factores se han categorizado mediante el método de clasificación cartográfica de la desviación estándar, a partir de la puntuación factorial de cada componente. Se pueden observar así, las diferencias existentes entre las regiones de la UE dependiendo de cada factor, de lo que se desprende a su vez las desigualdades regionales.

\section{La polarización de la riqueza}

El primer factor, nivel socioeconómico y cualificación, presenta una tendencia caracterizada por una mayor dispersión de los resultados entre 2009 y 2015, con un claro aumento de las regiones con valores extremos, particularmente aquellas con valores inferiores como resultado de los efectos de la crisis y las políticas de austeridad. Por un lado, los valores más elevados corresponden a NUTS situadas en la Dorsal Europea, desde el Sur británico hasta las regiones meridionales alemanas y austríacas (Figura $N^{\circ} 2$ ). Además, también destacan las regiones escandinavas y algunas megaciudades que se encuentran rodeadas de regiones con un menor nivel socioeconómico, como pueden ser los casos de Madrid, París, Berlín o Viena. Entre las regiones de mayor poder socioeconómico destaca Londres Central Oeste, uno de los principales polos del capitalismo financiero mundial que ha resultado ganadora en la crisis, donde la renta per cápita pasó de 137 mil €/ cápita en 2009 a 212 mil en 2015. En la cúspide de la riqueza en el ámbito europeo se han producido una serie de cambios que vale la pena señalar. Así, mientras que la provincia belga de Brabante Valón, Luxemburgo, Hovedstaden (Dinamarca) o Helsinki (Finlandia) se mantienen en la cima del poder económico, las regiones alemanas que había en el 2009 son reemplazadas por las británicas - Highlands e Islas, Escocia Nororiental, Cheshire, Dorset y Somerset, Devon y Londres Este-. De esta manera, se ve claramente como los principales espacios de acumulación de la riqueza se producen en aquellas regiones cuyos Estados no forman parte de la zona euro, así como en los principales centros financieros europeos (French et al., 2009). Además, las regiones del llamado Bloque Alemán, que comprende Alemania, Austria, Finlandia, Países Bajos y Dinamarca (Aglietta y Brand, 2015), resisten extraordinariamente los efectos de la crisis, sin trastocarse prácticamente su nivel socioeconómico. Ello es debido, entre otras cosas, a que Alemania ha aplicado políticas distintas a las que el Bundesbank ordenaba aplicar en el resto de países (Lehndorff, 2015). 
Por otro lado, las regiones con los niveles socioeconómicos y cualificación más bajos presentaban una clara demarcación periférica oriental y occidental en el inicio de la crisis en 2009 (figura 2). De esta manera, se pueden apreciar como los valores más bajos corresponden a las regiones de la Europa oriental que habían sufrido el profundo proceso de transición del socialismo real a diversas formas de capitalismo neoliberal. Estas regiones se caracterizan por los bajos salarios y la elevada preparación de la fuerza de trabajo, motivo por el que segmentos de la producción industrial alemana se deslocalizó (Lane \& Myant, 2007). Los efectos de la crisis en Alemania repercutieron rápidamente en las regiones orientales con el desplome de las exportaciones, lo que a su vez se tradujo en la profundización de la gran desigualdad en términos socioeconómicos respecto a la media europea. Sin embargo, la situación era diferente según los grados de inserción económica en la UE, adopción de la moneda única y estructuras político-económicas estatales. Así, se pueden distinguir los extremos de Polonia con una demanda interna mucho más potente, los países bálticos fuertemente afectados por el estallido de la burbuja inmobiliaria, y Rumanía y Bulgaria tremendamente expuestas a los vaivenes de la demanda exterior y del capital internacional. En cualquier caso, cabe subrayar que los primeros programas de austeridad aplicados en la UE se llevaron a cabo precisamente en las repúblicas bálticas y otros estados miembros orientales (Katel \& Raudla, 2013; Hardy, 2014).

Figura $\mathrm{N}^{\circ} 2$

Mapa del factor 1 (Nivel socioeconómico y cualificación), 2009-2015

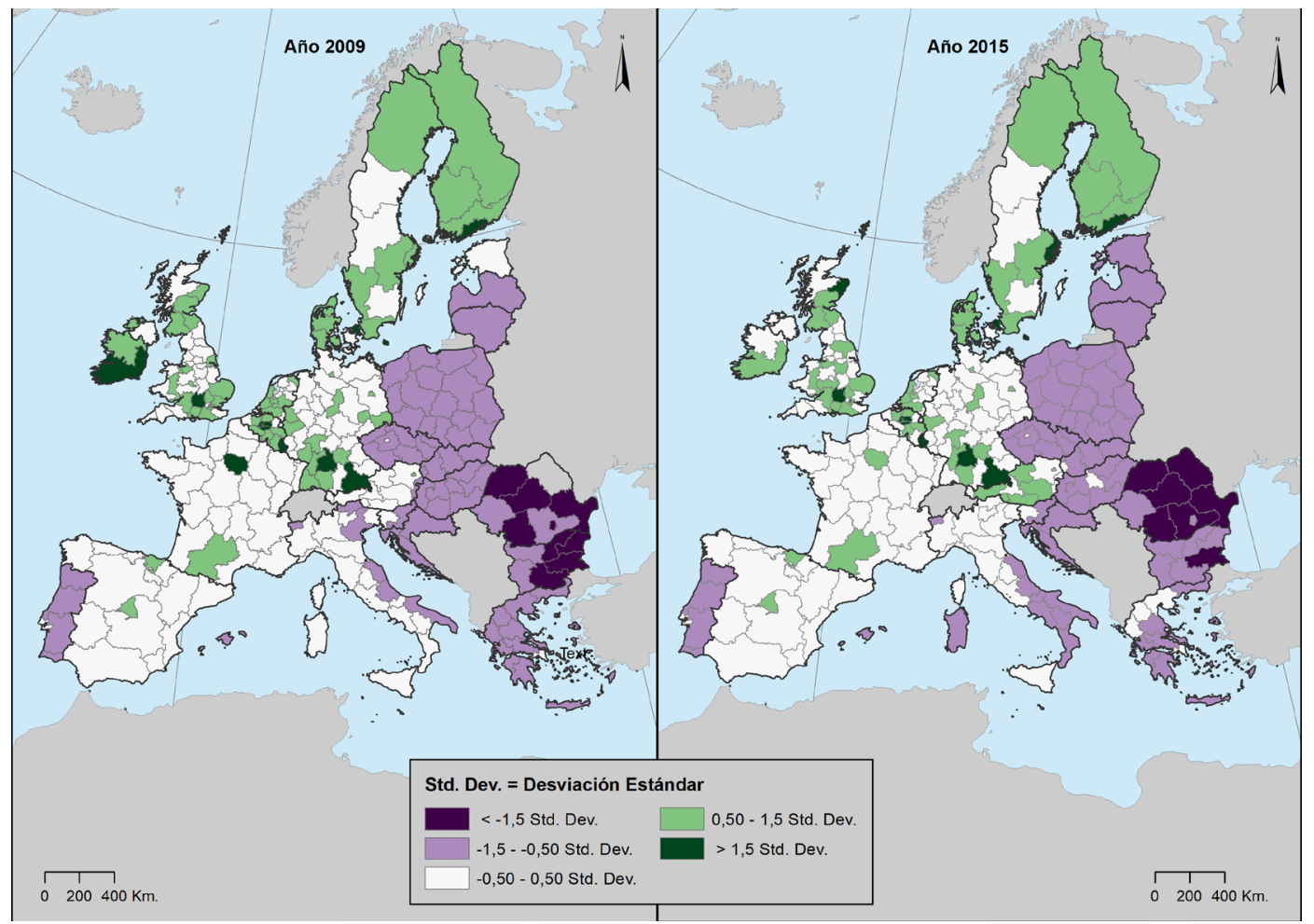

Fuente: elaboración propia. 
Asimismo, en la Figura $N^{\circ} 2$ se puede apreciar el avance del deterioro del nivel socioeconómico en el sur de la UE, especialmente en Portugal, Italia meridional y Grecia, mientras que en el caso español los valores más bajos corresponden al archipiélago balear. En cualquier caso, sorprende el hecho de que las regiones españolas se encuentren en torno a la media de la UE, lo que quedará matizado en el análisis del siguiente factor de precariedad y vulnerabilidad. Se puede destacar que, en el sur europeo, la mayor disparidad regional, en cuanto a nivel socioeconómico y cualificación, se producen en el Estado español e Italia, acentuándose en el 2015 a raíz de la aplicación de las medidas de austeridad. De esta manera, se comprueba como las políticas anticrisis aplicadas no han hecho más que intensificar las desigualdades regionales (Hadjimichalis, 2018).

\section{Hacia una Europa más precaria}

Durante los años de bonanza económica apenas se planteó el debate de la desigualdad y la enorme vulnerabilidad que acarreaba el modelo neoliberal en una UE que se iba ampliando y que se postulaba como una de las grandes potencias mundiales. Si entendemos el proyecto neoliberal como un proyecto de clase liderado por las élites con el objetivo de recomponer la tasa de beneficio y profundizar en las lógicas de mercantilización, eso solamente se ha podido realizar mediante el aumento de la desigualdad y la demonización de la clase trabajadora (Owen, 2011). Con el estallido de la crisis la desigualdad y precariedad se han disparado en Europa, y con ellas se ha recuperado el debate en torno a la cuestión de clase. En este sentido, el concepto de precariado ha cobrado gran relevancia política (Standing, 2011), y más allá de las críticas que se le han realizado (Hardy, 2017), lo recogemos al entender que nos es útil para recuperar la noción de clase trabajadora en contexto de crisis.

El factor precariedad laboral y vulnerabilidad social integra las variables de desempleo, hogares con poco trabajo, riesgo de pobreza y los jóvenes NINI (ni trabajan, ni estudian). Tal como señala la Comisión Europea la desigualdad está relacionada con la pobreza y la exclusión social, pudiéndose entender éstas como un reflejo de la desigualdad (EC, 2010). Así pues, el factor 2 también se podría entender como un factor de desigualdad. Los valores del factor 2 han experimentado entre 2009 y 2015 una mayor dispersión y además una redefinición espacial, siendo la variable que más ha cambiado la del desempleo con una mayor concentración de los valores más elevados en el sur de Europa. Además, tal como indicábamos, el factor 2 ha pasado de representar un 20,99\% de la varianza en 2009 al 28,59\% en 2015, cobrando fuerza tras el Crash de 2008 y las políticas de austeridad que han resultado ser portadoras de una mayor precariedad laboral y vulnerabilidad social.

En la Figura $N^{\circ} 3$ podemos apreciar como en el 2009, cuando la crisis se manifestaba más intensamente en los espacios centrales, fue cuando allí la vulnerabilidad y precariedad social fueron más elevadas. Destacan entre las regiones centrales las Midlands inglesas, Gales y regiones escocesas en Reino Unido y también las regiones belgas, situándose Bruselas entre las regiones más vulnerables de la UE. De hecho, en estos espacios contrastan los elevados valores del nivel socioeconómico con la elevada vulnerabilidad social. La aplicación de diferentes tipos de políticas anticrisis, combinando rescates bancarios con políticas expansivas del gasto social en un primer momento y de recorte en un segundo momento, fructificaron en el restablecimiento del crecimiento del PIB en las economías centrales de la UE. El crecimiento en esos espacios hizo que 
se recuperara el empleo, aunque con unas condiciones cada vez más precarias, y la explosión de la precariedad en la periferia europea ha hecho que en términos comparativos la precariedad, particularmente en Reino Unido, no se haya agravado en 2015. Sin embargo, la capital belga continuaba ocupando las primeras posiciones en cuanto a vulnerabilidad en 2015. Sin lugar a dudas, Bruselas es uno de los ejemplos más claros de polarización socioespacial. En Bruselas se produce una elevada disparidad entre los niveles de educación generalmente requeridos para un trabajo y el nivel educativo relativamente bajo de muchos habitantes, sobre todo aquellos de origen inmigrante que han sufrido la crisis de desempleo a largo plazo, manifestándose así la fragmentación entre los altos ejecutivos de empresas e instituciones de la UE y la gran masa de población inmigrante pobre (González et al., 2017).

Por otro lado, en 2009, las regiones menos vulnerables se localizaban en el centro de Europa, formando un cinturón en torno a las regiones del sur de Alemania, norte de Italia, Austria, Eslovenia, República Checa, Eslovaquia y algunas regiones polacas. A éstas cabría añadir otro cinturón septentrional con las regiones del norte de Bélgica, Países Bajos y el "Gran Copenhague" (Dinamarca y sur de Suecia). La mejor situación de partida de esas regiones, la recuperación del crecimiento y las políticas expansivas del gasto social hasta 2010, permitieron que buena parte del centro y norte de la UE mejoraran sus niveles de precariedad y vulnerabilidad en el 2015 (figura 3). Un aspecto que vale la pena subrayar es que a pesar de que se detecte una menor precariedad en estas regiones, la mayor concentración de la riqueza de la UE se produce precisamente en Países Bajos, Dinamarca, Alemania y Austria, mientras que Reino Unido presenta la mayor disparidad en la distribución de los ingresos en el conjunto de la UE (OECD, 2017). De todos modos, ya antes de la crisis se habían ido aplicando medidas de ajuste neoliberal que afectaban fundamentalmente a la clase trabajadora (p.ej. la Agenda 2010 en Alemania a partir de 2003), y sin embargo ha sido la crisis, la que ha servido de palanca para su profundización en las regiones centrales, destacando el caso francés donde se está desmontando el modelo social de bienestar (Lehndorff, 2015).

Finalmente, las regiones más vulnerables no siempre coinciden con aquellas con el nivel socioeconómico más bajo, sino que fundamentalmente se correlacionan con aquellas regiones más débiles dentro del sistema capitalista europeo, que experimentaron fuertes procesos especulativos además de los posteriores rescates bancarios. De esta manera, se pueden destacar las regiones irlandesas que en 2009 estaban subsumidas en una profunda crisis, ante la cual se desplegaron paquetes de ajuste que profundizaban su rol como espacio de baja fiscalidad societaria en la división espacial del trabajo de la UE (Lehndorff, 2015). En el sur de Europa nos encontramos con diferentes situaciones, pero podemos destacar como en el 2009, en Grecia todavía no se daban valores excesivamente altos de precariedad. En España e Italia los mayores valores se localizaban en las regiones más meridionales, mientras que Portugal presentaba unos valores medios. En cambio, con la transmutación de la crisis financiero-inmobiliaria en una crisis de deuda soberana, junto con la adopción de las políticas de austeridad se puede apreciar como en el 2015, la precariedad y vulnerabilidad aumentaron en Grecia, donde la Troika implementó en 2010 unas draconianas medidas supeditadas al pago a los acreedores (Lapavitsas y Flassbeck, 2015). Lo mismo puede apreciarse en España e Italia donde la depresión económica y las políticas austericidas se tradujeron en la expansión de la precariedad desde las regiones meridionales hacia las septentrionales. Las regiones del Sur de Europa que presentaban los valores más bajos son aquellas que tenían un mayor grado de obertura al capital internacional y mayor penetración de las lógicas turísticas de acumulación, como por ejemplo las Islas Baleares o Creta (Hadjimichalis, 2018). A esas regiones meridionales deberíamos añadir las de Rumania y Bulgaria que se adhirieron a la UE 
justo cuando terminó el período de euforia económica en 2007, presentando enormes diferencias socioeconómicas respecto a la mayor parte de Estados miembros (Gorzelak \& Goh, 2010).

Figura $\mathrm{N}^{\circ} 3$

Mapa del factor 2 (Precariedad laboral y vulnerabilidad social), 2009-2015

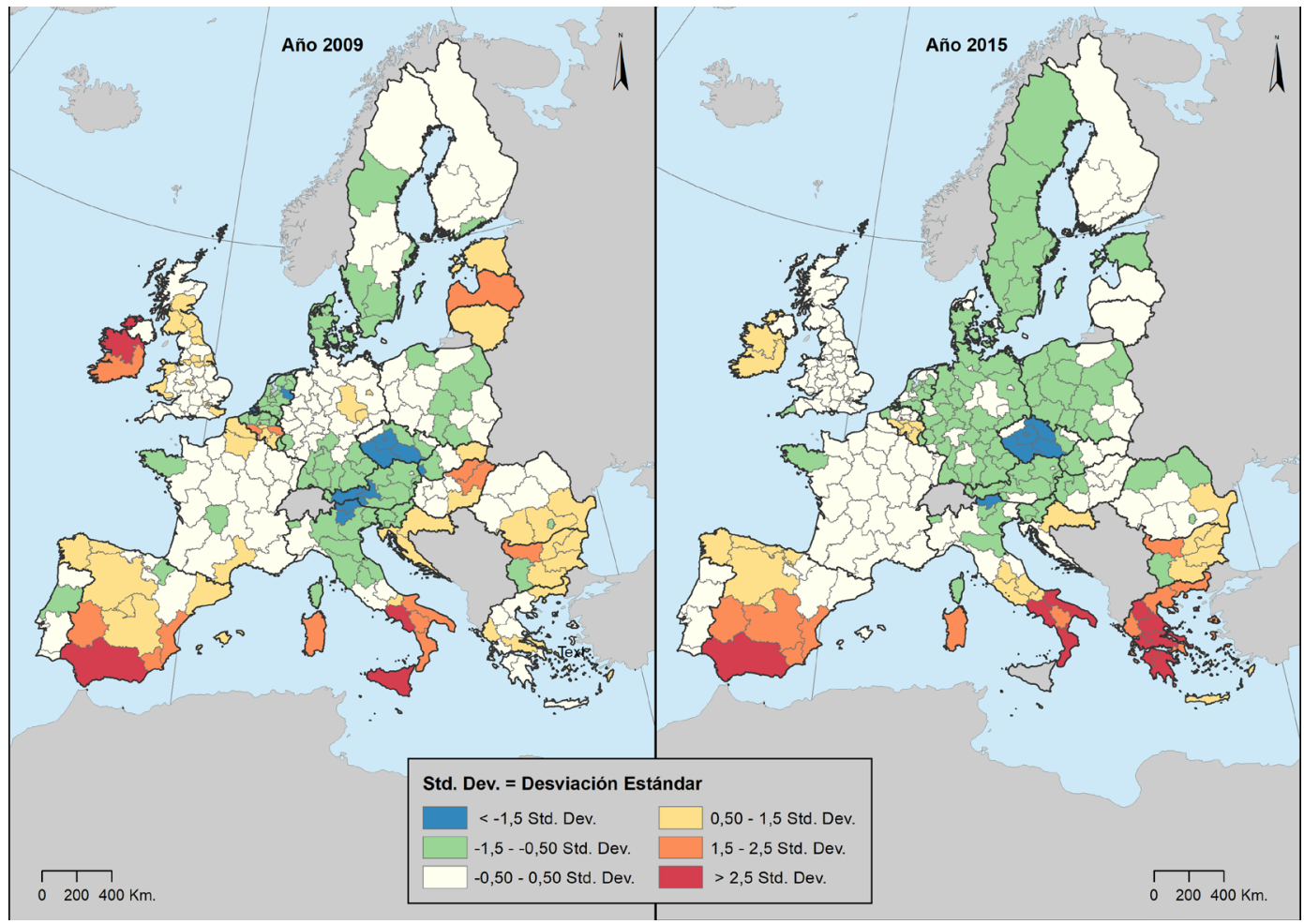

Fuente: elaboración propia.

\section{¿Una salida turística a la crisis?}

El tercer factor que hemos obtenido aglutina la ratio de pernoctaciones de turistas nacionales e internacionales por cada mil habitantes y la proporción del empleo turístico respecto del total, por lo que hemos denominado intensidad turística. El interés por incorporar esta dimensión en nuestro análisis radica, por un lado, en que el turismo se ha erigido a nivel internacional como una de las "soluciones" a la crisis global (Büscher \& Fletcher, 2017); y, por otro, al desplegar nuestro análisis desde el ámbito español, comprobamos como la salida de la crisis se ha planteado, entre otras cosas, mediante la profundización de la vía turística de acumulación (Murray et al., 2017).

Entre el 2009 y 2015 se produce un incremento de los valores tanto de empleo turístico como de la ratio de pernoctaciones, siendo el turismo una de las actividades más robustas de la UE. Los primeros síntomas de la crisis en los espacios centrales de la UE afectaron a la actividad turística, así la reducción del consumo turístico hizo que, según datos de EUROSTAT, el PIB de la rama de alojamiento cayera de 320 millones de euros a 207 millones entre 2008 y 2009 . Una vez recupe- 
radas las economías centrales se volvió a disparar la economía turística hasta alcanzar los 372 millones de euros en 2015, mientras que se alcanzaban cifras récord en pernoctaciones (2.784 millones) y plazas turísticas (31,18 millones). En la figura 4 se puede apreciar como en el 2009 tenemos un clara litoralización turística de las regiones mediterráneas españolas, francesas, croatas y griegas, a las que se deben añadir el Algarve portugués y los espacios insulares de Canarias y Madeira. La composición de estas regiones en torno al factor de la industria turística conforma en el mapa la división más limpia entre un sur geográfico, caracterizado por un clima más cálido y sueldos más bajos, y el norte de la UE de inviernos fríos y estíos frescos. En este cinturón turístico mediterráneo se incorporan también las regiones alpinas de Italia y las austríacas que corresponden fundamentalmente al turismo de invierno y de esquí. Además, en el Reino Unido sobresalen Cumbria con el Lake District National Park, Cornualles en el extremo sudoccidental que es uno de los resorts costeros más importantes del país, y las Highlands escocesas. De hecho, éste es un destacado ejemplo de turismo cultural y rural, el cual se ha llevado a cabo para la reconversión de territorios rurales en declive. Además, la elevada intensidad turística en las Highlands, se debe fundamentalmente al contraste entre elevadas pernoctaciones y escasa densidad demográfica (McCrone et al., 1995). En último lugar, en el norte de Europa solamente encontramos en una posición destacada Pomerania Occidental (Alemania), donde se encuentran los más antiguos resorts turísticos alemanes del Báltico (Gormsen, 1997).

Figura $\mathrm{N}^{\circ} 4$

Mapa del factor 3 (intensidad turística), 2009-2015

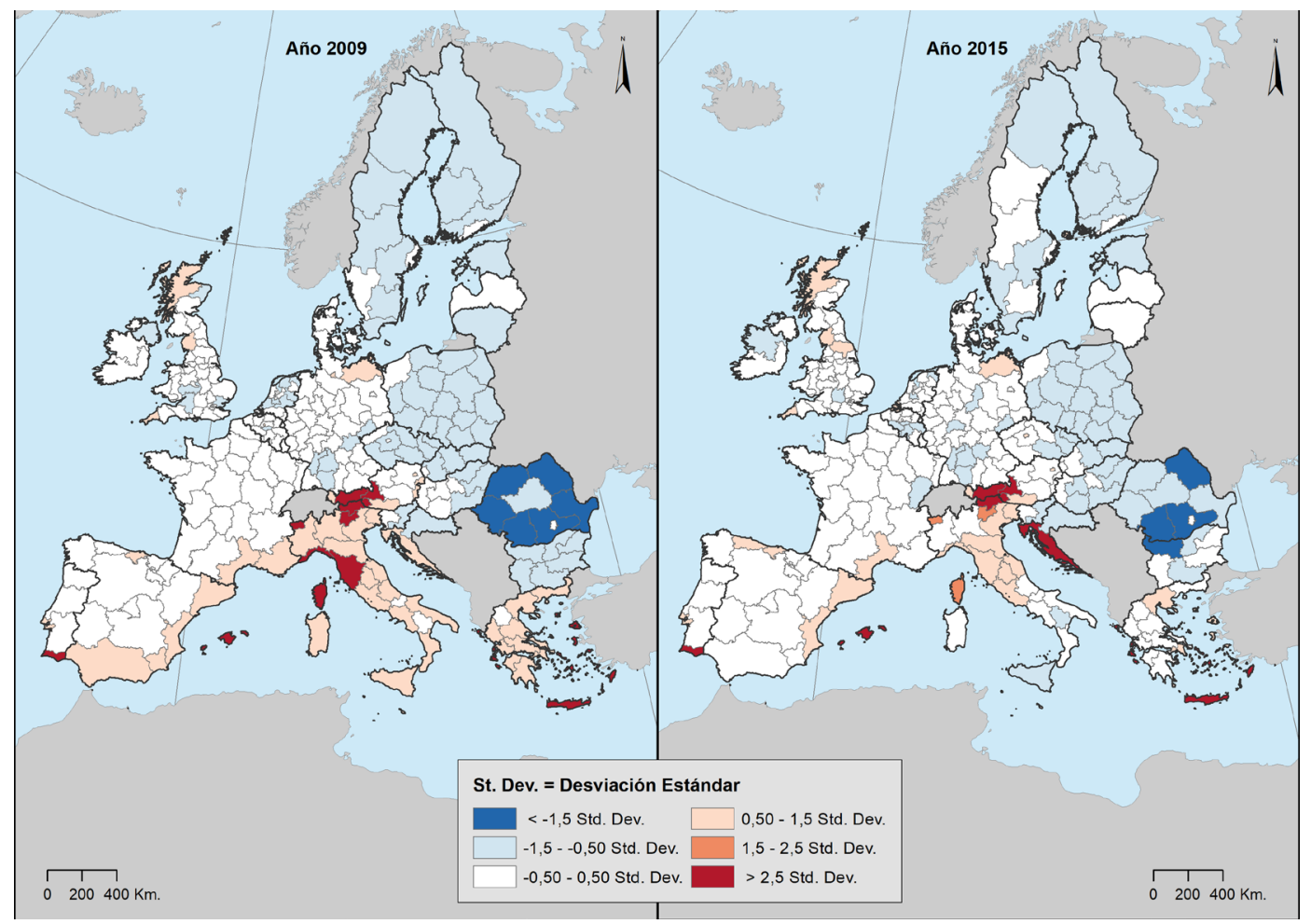

Fuente: elaboración propia. 
En el 2015 se observa un relativo cambio en el mapa de la intensidad turística con un aumento de las NUTS-2 con valores de intensidad turística próximos a la media, y manteniéndose los elevados resultados de los archipiélagos del Sur de Europa, la costa dálmata y el extraordinario empuje turístico de Austria (Figura $\mathrm{N}^{\circ} 4$ ). Un elemento destacable, a pesar de que todavía se registran elevados valores de intensidad turística, es la pérdida de peso relativo en este factor de las regiones meridionales de España, provincias del sur de Italia y de la Grecia continental. Ello nos sugiere que los aumentos en la intensidad turística se han llevado a cabo de manera muy concentrada, particularmente en los espacios insulares. Asimismo, una cuestión que merece la pena subrayar es la estrecha correlación entre la elevada intensidad turística y un nivel socioeconómico bajo, con las excepciones austríaca y corsa. Por último, las regiones con una menor relevancia turística se corresponden en ambos momentos a las de la Europa oriental y de la península escandinava, debido a una combinación de factores como son las condiciones climáticas, escaso despliegue de infraestructuras turísticas, o la especialización industrial en el caso de las regiones del este. De hecho, con la ampliación de la UE hacia el este se reforzaron las pautas de desindustrialización del sur de Europa y ello se tradujo en la potenciación de estrategias de acumulación rentistas, alimentadas por el turismo y las burbujas inmobiliarias (Hadjimichalis, 2018). Ese aumento de la intensidad turística y su mayor concentración se debe en buena medida a los efectos del desplome turístico en el norte de África y Turquía. Además, los procesos de devaluación interna han hecho que se mantenga una de las principales premisas para la penetración turística: mano de obra barata (Eisenschitz, 2016).

\section{El mosaico regional europeo tras el austericidio ${ }^{6}$}

Desde el inicio de la crisis en la UE, las políticas han basculado entre un primer paquete de medidas de corte keynesiano, entre las cuales se encontraban los rescates a la banca, y otro de corte "austericida" desplegado a partir de 2010 cuando la crisis mutó en una crisis de deuda soberana (Schäfer \& Streeck, 2013). Tal como señala Streeck (2017), la ruptura del capitalismo de postguerra y el ascenso del marco de regulación neoliberal se ha apoyado en el llamado "Estado consolidador", que sustituye al Estado democrático con el fin de consolidar las finanzas públicas mediante recortes fiscales y de gasto público, sustituyendo las fuentes de ingresos por emisión de deuda, que a la postre beneficia al capital financiero. En este sentido, uno de los pilares de la UE se articuló sobre los techos de déficit ( $3 \%$ del PIB) y deuda pública ( $60 \%$ del PIB). Asimismo, la interconexión de los mercados de capitales ha permitido canalizar los superávits comerciales a través de productos financieros, que en el caso de la UE se tradujo en un aumento espectacular de los préstamos por parte de entidades alemanas, particularmente, a los Estados del sur (Streeck, 2017). En la Figura N 5 se puede comprobar como buena parte de los Estados centrales de la UE superaban claramente el techo de deuda en el 2009, mientras que otros del sur como España estaban por debajo. Sin embargo, en 2015, los niveles de deuda aumentaron notablemente en prácticamente toda la eurozona, destacando España donde parte de la deuda privada se trans-

El término austericidio define el período a partir del cual se empezaron a desplegar en la UE toda una serie de políticas de recortes presupuestarios, que afectaban principalmente a las esferas del llamado estado del bienestar, y que se combinaron con políticas de ajuste y privatización de servicios públicos, particularmente en los estados más afectados por la crisis. Este periodo se despliega, particularmente, a partir de 2010, cuando el capital financiero intensificó los ataques especulativos sobre la deuda pública y la Troika (Comisión Europea, Banco Central Europeo y Fondo Monetario Internacional) intervino políticamente los "estados fallidos" de la UE. Así, se impuso políticamente el pago de la deuda como eje prioritario de la política europea (Seymour, 2014; Holland, 2016). 
formó en pública. Los acreedores, fundamentalmente Alemania, han cobrado un protagonismo extraordinario en el contexto de la UE, y la deuda ha sido utilizada como arma política para llevar a cabo una selectiva agenda de ajuste orientada a satisfacer el pago de la deuda. En definitiva, la cuestión no es tanto cuan endeudado está un país, sino quienes son los amos del capital, y por eso la deuda no es un tema tan crucial en Alemania o Reino Unido (Hadjimichalis, 2018).

Figura 5

Mapa de la deuda pública, 2009-2015

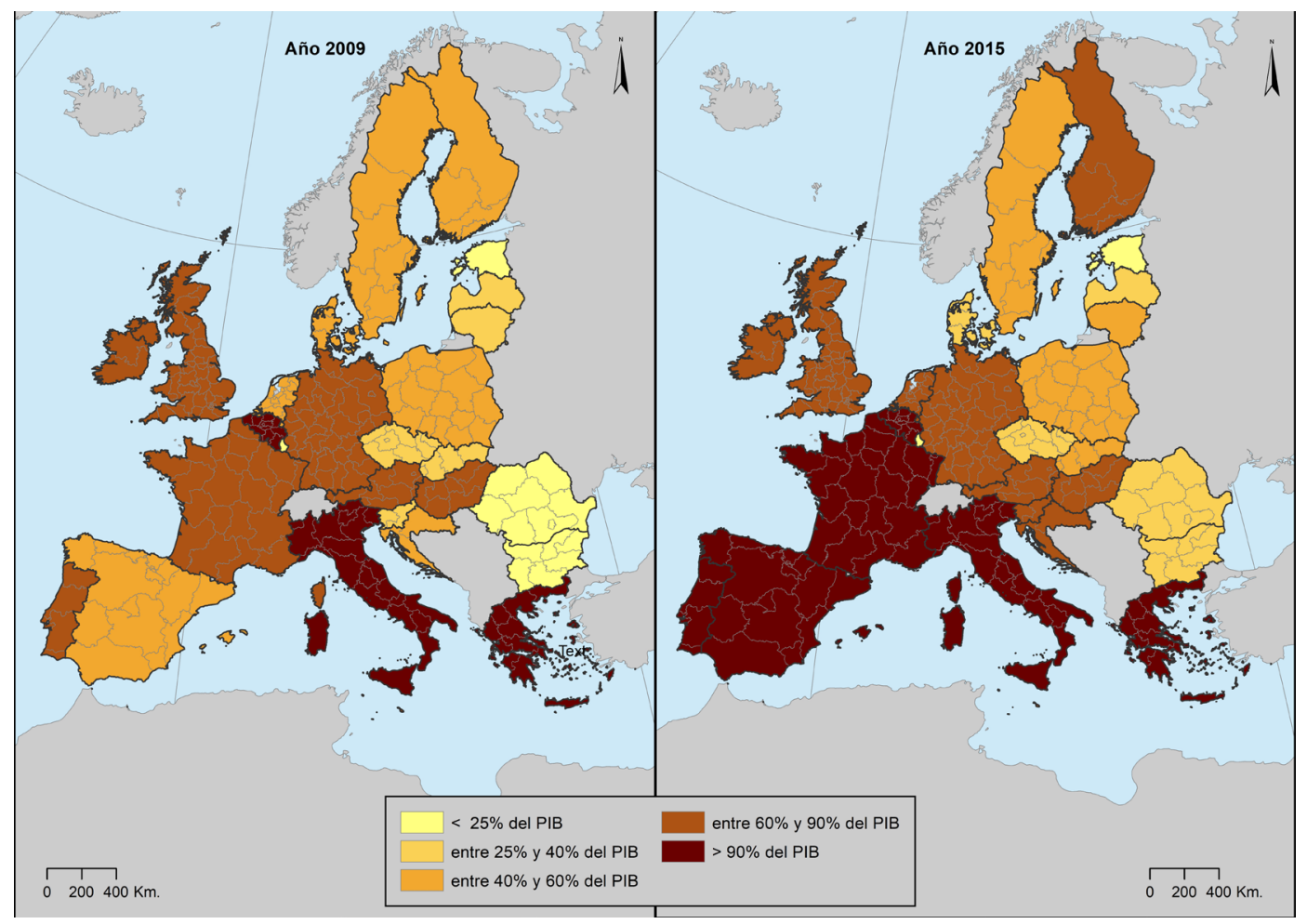

Fuente: Elaboración propia a partir de EUROSTAT.

Una vez analizados los diferentes factores y expuesto brevemente la compleja realidad de la deuda en la UE, pasamos a presentar los resultados del análisis clúster de las NUTS-2 del año 2015 (Figura $\mathrm{N}^{\circ} 6$ ). El principal objetivo detrás de las agrupaciones regionales radica en el hecho que, además de los Estados como unidad de acción política tal como señala Lehndorff (2015), pensamos que es crucial atender a los diferentes procesos de articulación socioespacial desde una perspectiva transescalar. Además, tal como se ha justificado anteriormente, nos interesa particularmente distinguir regiones con cierta intensidad turística, en función del nivel socioeconómico y de precariedad.

En un primer lugar, tenemos el grupo de regiones con un nivel socioeconómico medio, intensidad turística medio-alta y precariedad media que forman un cinturón que va desde el norte de España (Navarra y Aragón), pasando por la Costa Azul de Francia, norte y centro de Italia y sur de Austria. A estas regiones se deben añadir las NUTS con mayor intensidad turística de Reino Unido, Países Bajos y Alemania. Un segundo grupo está compuesto por aquellas regiones que presentan un nivel socioeconómico medio-alto y baja precariedad que se corresponde con la mayor parte 
de las NUTS de Francia, Alemania y Suecia. En tercer lugar, tenemos un grupo que hemos definido por su alto nivel socioeconómico y que está formado por las NUTS alrededor de la zona metropolitana de Londres, norte de Bélgica y Randstad holandés, sur alemán y Brunswick en el centro de Alemania donde grandes empresas tienen su sede, Copenhague y Suecia meridional, y Finlandia. En este grupo podemos destacar las NUTS belgas y británicas al combinar un nivel socioeconómico alto con una precariedad y vulnerabilidad elevadas.

En cuarto lugar, podemos subrayar como en el caso de la mayor parte de las NUTS de la Europa del este se agrupan en torno a la categoría de nivel socioeconómico bajo, escasa precariedad y una exigua intensidad turística. Una de las explicaciones a la existencia de esa baja precariedad reside en el hecho que, a pesar de haber adoptado políticas de ajuste neoliberal, en dichas regiones todavía persisten elementos de fricción procedentes del socialismo real que han impedido, en cierta manera, el avance desbocado de la precariedad (Hardy, 2014; Lehndorff, 2015). Un quinto grupo estaría compuesto por aquellas regiones con nivel socioeconómico y precariedad medio-altos. Un grupo que encontramos fundamentalmente en el Reino Unido e Irlanda, que se extiende por buena parte de la Dorsal Europea sobre NUTS belgas y francesas, y a las que se añaden la Comunidad de Madrid, País Vasco y La Rioja en España.

Figura $N^{\circ} 6$

Mapa clusters 2015

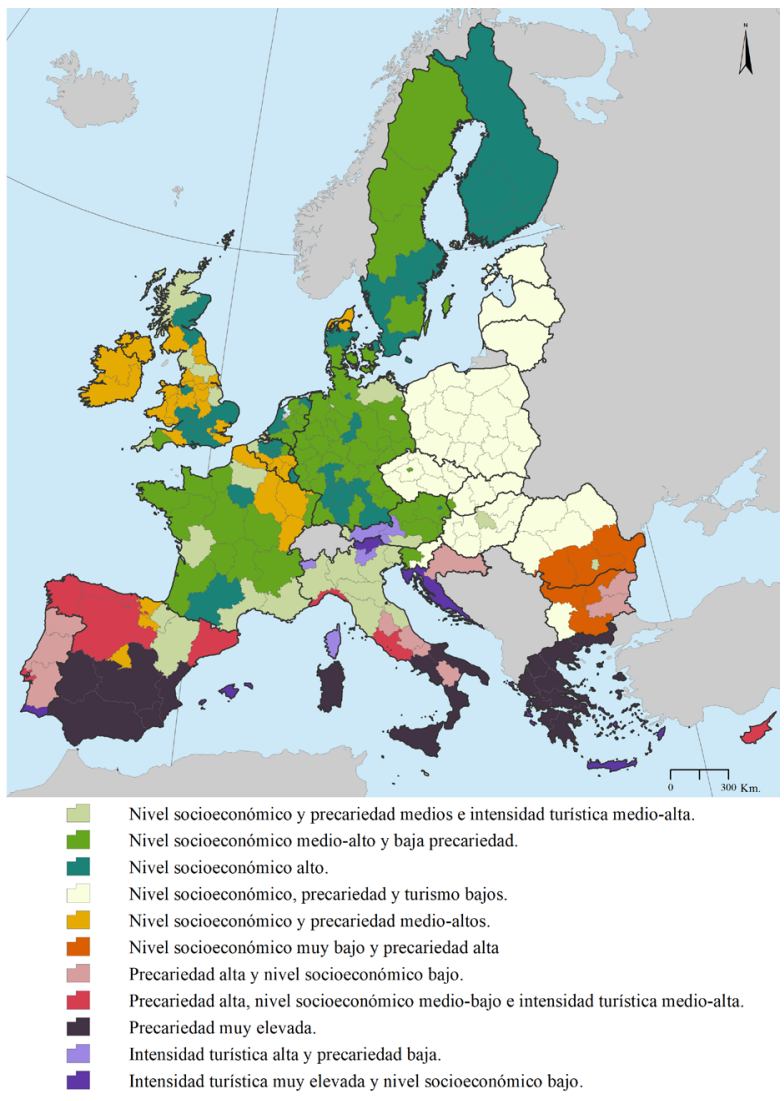

Fuente: Elaboración propia. 
En cuanto a las NUTS en base a un notable nivel de precariedad, podemos distinguir cuatro grupos. El primero pertenece a aquellas regiones del sur de Rumanía, excepto Bucarest, y el interior de Bulgaria con los niveles socioeconómicos más bajos de la UE y con elevada precariedad. Un segundo grupo de precariedad alta y nivel socioeconómico bajo que se extiende prácticamente por todo Portugal, las zonas de interior del centro y sur de Italia, Croacia interior y la costa búlgara. En tercer lugar, se distinguen regiones que presentan valores altos de precariedad con una intensidad turística medio-alta, entre las que se encuentran las de la parte septentrional de España, incluida Cataluña, Lisboa y Madeira en Portugal, Riviera italiana o Chipre. Finalmente, tenemos un cinturón sud-mediterráneo con una precariedad muy elevada ocupando las NUTS del sur de España, Italia y Grecia continental. Estas regiones son las más castigadas por la crisis y las políticas de austeridad, de las cuales podemos destacar la Comunidad de Valencia como epítome de la burbuja inmobiliaria y sus devastadores efectos (Naredo y Montiel, 2011).

En último lugar, tenemos dos grupos que destacan por su elevada intensidad turística. El primero de ellos corresponde a aquellas NUTS donde al mismo tiempo que se da una elevada intensidad turística, se dan unos valores de precariedad bajos. Este grupo pertenece fundamentalmente a las regiones de Austria, norte de Italia y Córcega. Y, finalmente, tenemos una serie de NUTS con los valores de intensidad turística más altos que combinan con un nivel socioeconómico bajo, la mayor parte de las cuales pertenecen a los espacios insulares de los Estados meridionales, como por ejemplo las Islas Baleares o Canarias en España, Creta en Grecia, además del Algarve en Portugal o la región costera de Croacia.

\section{Conclusiones}

La UE está compuesta por una geografía entramada en centenares de regiones heterogéneas y diversas, unidas entre ellas bajo un marco teórico de convergencia unitaria, pero que en la práctica se traduce en una unión monetaria y una desunión político-económica. Desde el enfoque del desarrollo geográfico desigual se puede comprobar como el proyecto de la UE se ha construido de espaldas a la geografía. El enfoque neoliberal sobre el que se ha articulado la UE se asienta sobre una perspectiva antigeográfica que responde a los intereses de las élites europeas y sus Estados hegemónicos.

En el trabajo hemos podido comprobar como el desarrollo geográfico desigual es una dinámica real, que se reproduce en el tiempo y que se expande espacialmente, cabalgando sobre la economía capitalista, mientras que escinde, a su paso, a sociedades y territorios. La UE se ha articulado como una unión de Estados que compiten entre sí y dónde éstos son los principales actores políticos. Sin embargo, el análisis infraestatal nos arroja una geografía mucho más heterogénea, y ésta tiene que jugar un papel clave en la comprensión de las geografías dinámicas de la UE, y sobre todo de cara a la articulación de una construcción política del espacio europeo que atienda a las diferencias y desigualdades territoriales.

Con el estallido de la crisis y las políticas de austeridad se han reactivado los enfoques críticos sobre la UE, al mismo tiempo que las desigualdades socioespaciales pre-existentes se han intensificado. Tal como se expresa en nuestros resultados, más que de una Europa, podemos hablar de múltiples Europas claramente diferenciadas. Un aspecto a destacar es que las regiones más 
turísticas de la UE presentan también unos niveles socioeconómicos muy bajos, y la precariedad se ve moderada por los efectos de la economía turística en el empleo. No obstante, se trata de empleos cada vez más precarios y peor remunerados. Paradójicamente, la crisis europea se ha saldado con "el triunfo de las ideas fracasadas" (Lehndorff, 2015), y la sociedad avanza, tal como ha señalado Streeck (2017), hacia un "interregno postcapitalista" caracterizado por un progresivo desorden sistémico, como resultado del éxito del capitalismo y la intensificación de sus contradicciones. En este contexto, se han acentuado las políticas post-democráticas y se han reforzado los movimientos de extrema derecha de corte euroescéptico.

Ante un escenario de tal calibre, se han planteado diferentes opciones políticas de izquierdas que basculan entre la formulación de un new deal verde para la UE (Aglietta y Brand, 2015) y la ruptura del euro y la desintegración de la UE (Lapavitsas \& Flassbeck, 2015). En cualquier caso, una política emancipadora y de izquierdas para la UE debería tener en cuenta la compleja y desigual geografía de la UE y cuáles son los mecanismos que activan y refuerzan ese desarrollo geográfico desigual. En esa línea, los movimientos surgidos en las plazas del sur de Europa han apuntado la condonación de la deuda como un primer paso, seguido por la reconceptualización de las relaciones socio-espaciales en base a planteamientos radicalmente democráticos, lo que implica la confinación de la economía política neoliberal al baúl de la historia (Hadjimichalis, 2018). En definitiva, la crisis y su plasmación en el espacio europeo ilustra que en contra de lo que propugna el dogma neoliberal, la geografía sí importa.

\section{Referencias bibliográficas}

AGLIETTA, M. y BRAND, T. Un New Deal para Europa. Crecimiento, euro, competitividad. Madrid: Traficantes de Sueños, 2015.

ALBERTOS, J.M. y SÁNCHEZ, J.L. (coordinadores). Geografía de la crisis económica en España. Valencia: Universitat de València, 2014.

ALGUACIL, J.; CAMACHO, J. y HERNÁNDEZ, A. La vulnerabilidad urbana en España. Identicación y evolución de los barrios vulnerables. Empiria, 2014, № 27, p. 73-94.

AMIN, S. El desarrollo desigual: ensayo sobre las formaciones sociales del capitalismo periférico. Barcelona: Fontanella, 1974.

BOSQUE, J. y MORENO, A. Prácticas de análisis exploratorio y multivariante de datos. Barcelona: Oikos-tau, 1994.

BRENNER, N. Globalisation as Reterritorialisation: The Re-scaling of Urban Governance in the European Union. Urban Studies, 1999, Vol. 36, N³, p. 431-451.

BÜSCHER, B. \& FLETCHER, R. Destructive creation: capital accumulation and the structural violence of tourism. Journal of Sustainable Tourism, 2017, Vol. 25, No 5, p. 651-667.

DESAI, R. (editor). Analyticial Ggains of Geopolitical Economy. Bingley: Emerald, 2016. 
DUNFORD, M. \& LIU, W. Uneven and combined development. Regional Studies, 2017, Vol. 51, № 1, p. 69-85.

EISENSCHITZ, A. Tourism, class and crisis. Human Geography, 2016, Vol. 9, No 3, p. 110-124.

EUROPEAN COMMISSION (EC). Why socio-economic inequalities increase? Luxembourg: European Commission, 2010.

FERNÁNDEZ-DURÁN, R. La compleja construcción de la «Europa» superpotencia. Barcelona: Virus, 2005.

FRENCH, S.; LEYSHON, A. y THRIFT, N. A very geographical crisis: the making and breaking of the 2007-2008 financial crisis. Cambridge Journal of Regions, Economy and Society, 2009, Vol.2, No 1, p. 287-302.

GARCÉS, J. Soberanos e intervenidos. Estrategias globales, americanos y españoles. Madrid: Siglo XXI, 2008.

GONZÁLEZ, S. The North/South divide in Italy and England: Discursive construction of regional inequality". European Urban and Regional Studies, 2011, Vol. 18, N 1, p. 62-76.

GONZÁLEZ. S.; OOSTERLYNCK. S.; RIBERA-FUMAZ. R. \& ROSSI. U. Locating the global financial crisis: variegated neoliberalization in four European cities. Territory, Politics, Governance (in press), 2017, p. 1-21.

GORMSEN, E. The impact of tourism on coastal areas. GeoJournal, 1997, Vol. 1, No 42, p. 39-54.

GORZELAK, G. \& GOH, C. (editors). Financial Crisis in Central and Eastern Europe: From Similarity to Diversity. Opladen: Barbara Budrich Publishers, 2010.

HADJIMICHALIS, C. Uneven Development and regionalism: State, Territory and Class in Southern Europe. London: Croom Helm, 1987.

HADJIMICHALIS, C. Uneven geographical development and socio-spatial justice and solidarity: European regions after the 2009 financial crisis. European Urban and Regional Studies, 2011, Vol. $18, N^{\circ} 3$, p. 254-274.

HADJIMICHALIS, C. Crisis Spaces: Structures, Struggles and Solidarity in Southern Europe. New York: Routledge, 2018.

HADJIMICHALIS, C. \& HUDSON, M. Contemporary Crisis Across Europe and the Crisis of Regional Development Theories. Regional Studies, 2014, Vol. 48, No 1, p. 208-218.

HARDY, J. Transformation and crisis in Central and Eastern Europe: A combined and uneven development perspective. Capital \& Class, 2014, Vol. 38, № 1, p. 143-155. 
HARDY, J. (Re)conceptualising precarity: institutions, structure and agency. Employee Relations, 2017, Vol. 39, N³, p. 263-273.

HARVEY, D. Limits to Capital. London: Verso, 2006 [1982].

HARVEY, D. The Enigma of Capital. And the Crises of Capitalism. Oxford: Oxford University Press, 2010.

HARVEY, D. Seventeen contradictions and the end of capitalism. London: Profile Books, 2014.

HOLLAND, S. Contra la hegemonía de la austeridad. Barcelona: Arpa, 2016.

KATEL, R. \& RAUDLA, R. The Baltic Republics and the Crisis of 2008-2011. Europe-Asia Studies, 2013, Vol. 65, N³, p. 426-449.

KEEN, S. Debunking Economics. The Naked Emperor Detrhoned? London: Zed Books, 2011.

KOTZEVA, M. (editor). Eurostat Regional Yearbook. Luxemburg: Publications Office of the European Union, 2016.

LANE, D. \& MYANT, M. (editors). Varieties of Capitalism in Post-Communist Economies. Hampshire and New York: Palgrave MacMillan, 2007.

LAPAVITSAS, C. Crisis in the Eurozone. London: Verso, 2012.

LAPAVITSAS, C. y FKASSBECK, H. Contra la Troika. Crisis y austeridad en la Eurozona. Madrid: Ediciones AKAL, 2015.

LEHNDORFF, S. (editor). El triunfo de las ideas fracasadas. Modelos del capitalismo europeo en crisis. Madrid: Fuhem Ecosocial y Libros La Catarata, 2015.

MASSEY, D. Spatial Divisions of Labor: Social Structures and the Geography of Production. New York: Routledge, 1995 [1984].

MCCRONE, D.; MORRIS, A. \& KIELY, R. Scotland - The Brand: The Making of Scottish Heritage. Edinburgh: Edinburgh University Press, 1995.

MÉNDEZ, R.; ABAD, L.D. y ECHAVES, C. Atlas de la crisis. Impactos socioeconómicos y territorios vulnerables en España. Valencia: Tirant Humanidades, 2015.

MURRAY, I. Capitalismo y turismo en España. Del "milagro económico" a la "gran crisis". Barcelona: Alba Sud, 2015.

MURRAY, I.; YRIGOY, I. \& BLÁZQUEZ-SALOM, M. The role of crises in the production, destruction and restructuring of tourist spaces. The case of the Balearic Islands. Investigaciones Turísticas, 2017, No 13, p. 1-29. 
NAREDO, J.M. La economía en evolución. Madrid: Siglo XXI, 2015 [1987].

NAREDO, J.M. y MONTIEL, A. El modelo inmobiliario español y su culminación en el caso valenciano. Barcelona: Icaria, 2011.

ORGANISATION FOR ECONOMIC CO-OPERATION AND DEVELOPMENT (OECD). Understanding the socio-economic divide in Europe 2017. Disponible en Internet:

http://oe.cd/cope-divide-europe-2017.

OWEN, J. Chavs. The demonization of the working class. London: Verso, 2011.

PIKETTY, T. El capital en el siglo XXI. México: FCE, 2014.

ROGERSON, P.A. Statistical Methods for Geography. London: SAGE, 2014.

SANTOS, J.M. y GARCÍA, F.J. Análisis estadístico de la información geográfica. Madrid: UNED, 2008.

SCHÄFER, A. \& STREECK, W. (editors). Politics in the Age of Austerity. Cambridge: Wiley, 2013.

SEYMOUR, R. Against Austerity. How We Can Fix the Crisis They Made. London: Pluto Press, 2014.

SHAIKH, A. Capitalism. Competition, Conflict, Crises. New York: Oxford University Press, 2016.

SMITH, A. Europe and inter-dependent world: Uneven geo-economic and geo-political developments. European Urban and Regional Studies, 2012, Vol. 20, No 1, p. 3-13.

SMITH, N. Uneven Development: Nature, Capital, and the Production of Space. London: Verso, 2010 [1984].

STANDING, G. The Precariat. London: Bloomsbury Academic, 2011.

STREECK, W. ¿Cómo terminará el capitalismo? Madrid: Traficantes de Sueños, 2017.

SUBASAT, T. (editor). The great financial meltdown. Systemic, conjunctural or policy created? Cheltenham: Edward Elgar, 2016.

VAROUFAKIS, Y. El Minotauro global. Debolsillo: Barcelona, 2012.

VILÀ, R.; RUBIO, M.J.; BERLANGA, V. y TORRADO, M. 2014. Cómo aplicar un clúster jerárquico en SPSS. REIRE. Revista d'Innovació i Recerca en Educació, 2014, Vol. 7, No 1, p. 113-127.

WALLERSTEIN, I. El moderno sistema mundial: la agricultura capitalista y los orígenes de la economíamundo europea en el siglo XVI. Madrid: Siglo XXI, 1979.

WILKINSON, R. \& PICKETT, K. The spirit level. Why equality is better for everyone. London: Penguin Books, 2010.

WYLY, E. Positively Radical. International Journal of Urban and Regional Research, 2011, Vol. 35, No 5, p. 889-912. 